\title{
A Cross-Sectional Study of Porcine Reproductive and Respiratory Syndrome Virus and Mycoplasma hyopneumoniae in Wild Boars Reared in Different Types of Captive Setting in Thailand
}

Anuwat Wiratsudakul'*, Phirom Prompiram ${ }^{1}$, Kanaporn Pholtep ${ }^{1}$, Siriporn Tantawet ${ }^{2}$, Duangkhamon Suraruangchai ${ }^{3}$, PoonyapatSedwisai ${ }^{1}$ NareeratSangkachai ${ }^{1}$ and Parntep Ratanakorn ${ }^{1}$

${ }^{1}$ The Monitoring and Surveillance Center for Zoonotic Diseases in Wildlife and Exotic Animals, Faculty of Veterinary Science, Mahidol University, 999 Putthamonthon 4 Rd., Salaya, Nakhon Pathom 73170, Thailand

${ }^{2}$ Department of Clinical Science and Public Health, Faculty of Veterinary Science, Mahidol University, 999 Putthamonthon 4 Rd., Salaya, Nakhon Pathom 73170, Thailand

${ }^{3}$ Graduate Student, Department of Veterinary Pathology, Faculty of Veterinary Sciences, Chulalongkorn University Henri-Dunant Rd., Pathumwan Bangkok 10330, Thailand

\begin{abstract}
Porcine reproductive and respiratory syndrome virus and Mycoplasma hyopneumoniae are account as economically important pathogens in swine business worldwide. The studies of these two pathogens in Thailand were restricted on domestic pigs in swine industry and the status of these pathogens in wild boars is currently not available. This cross-sectional study aimed at estimating the seroprevalence of antibodies to these agents in captive wild boars. Fifty-two serum samples were collected from wild boars reared in three different types of captive settings including a commercial wild boar farm, a wildlife breeding research station and a zoo. All serum samples were examined for antibodies to porcine reproductive and respiratory syndrome virus and Mycoplasma hyopneumoniae by ELISA methods. The results revealed that the highest true prevalence of both pathogens was found in sera derived from wild boars in wildlife breeding research station at 69 and $66 \%$ for porcine reproductive and respiratory syndrome virus and Mycoplasma hyopneumoniae respectively. This study is the first to reveal seroprevalence of antibodies against porcine reproductive and respiratory syndrome virus and Mycoplasma hyopneumoniaein wild boar populations in Thailand. More detailed investigations are critically needed.
\end{abstract}

Keywords: Captive wild boar; Mycoplasma hyopneumoniae; PRRSV; Seroprevalence; Thailand

\section{Introduction}

Porcine reproductive and respiratory syndrome virus (PRRSV) and Mycoplasma hyopneumoniae are account as economically important pathogens worldwide [1,2]. Both genotype 1 and genotype 2 of PRRSV were detected in domestic pig farms in all regions of Thailand. Prevalence of PRRSV in domestic pigs in the country varied from $24.6-53.6 \%$ and the prevalence was $32.7 \%$ in the central region [3] where the density of domestic pig population is high. The recorded pig density in this region according to previous study was between 0.00 and 777.56 heads per square kilometer [4]. Nonetheless, the clusters of PRRSV were not associated with geographic distribution of the virus. The identical viruses were present in different provinces [5]. The PRRSV infected pigs are often co-infected with M. hyopneumoniae and other agents causing porcine respiratory disease complex (PRDC) $[2,3]$. The prevalence $M$. hyopneumoniae was previously reported at $2.08-45.00 \%$ in domestic pigs in Thaiand [6]. There was evidence suggesting that both PRRSV and M. hyopneumoniae can be transmitted via airborne over long distance up to $9.2 \mathrm{~km}$ from the source herd [7]. The exchange of these two agents between domestic pigs and wild boars might exist in Thailand especially in the high density area of pig production in the central region.

Wild boars are reared in Thailand for many purposes such as research activities, exhibition in the zoos and selling as exotic meat. At least three types of captive wild boar settings were recognized in Thailand including wildlife breeding research station, zoo and commercial wild boar farm [8]. However, the studies of PRRSV and M. hyopneumoniae in Thailand were restricted on domestic pigs in swine industry. Hence, the epidemiological status of these two pathogens in wild boars (Sus scrofa) is currently not available in the country.

Therefore, this preliminary cross-sectional study aimed to initiate infectious disease study in wild boars by estimating seroprevalence of antibodies against PRRSV and M. hyopneumoniae in captive wild boars reared in different types captive settings.

\section{Materials and Methods}

\section{Sample collection}

Three wild boar captive settings were conventionally selected to represent each type of wild boar rearing. A wildlife breeding research station and a zoo are located in two major pig-producing provinces in the central region namely Ratchaburi province and Chonburi province respectively. These two provinces were recorded

*Corresponding author: Anuwat Wiratsudakul, The Monitoring and Surveillance Center for Zoonotic Diseases in Wildlife and Exotic Animals, Faculty of Veterinary Science, Mahidol University, 999 Putthamonthon 4 Rd., Salaya, Nakhon Pathom 73170, Thailand, Tel/Fax: +6624415238; E-mail: anuwat.wir@mahidol.ac.th

Received October 24, 2013; Accepted November 25, 2013; Published November 28, 2013

Citation: Wiratsudakul A, Prompiram P, Pholtep K, Tantawet S, Suraruangchai D, et al. (2013) TA Cross-Sectional Study of Porcine Reproductive and Respiratory Syndrome Virus and Mycoplasma hyopneumoniae in Wild Boars Reared in Different Types of Captive Setting in Thailand. J Veterinar Sci Technol 4: 146. doi:10.4172/2157-7579.1000146

Copyright: $\odot 2013$ Wiratsudakul A, et al. This is an open-access article distributed under the terms of the Creative Commons Attribution License, which permits unrestricted use, distribution, and reproduction in any medium, provided the original author and source are credited. 
Citation: Wiratsudakul A, Prompiram P, Pholtep K, Tantawet S, Suraruangchai D, et al. (2013) TA Cross-Sectional Study of Porcine Reproductive and Respiratory Syndrome Virus and Mycoplasma hyopneumoniae in Wild Boars Reared in Different Types of Captive Setting in Thailand. J Veterinar Sci Technol 4: 146. doi:10.4172/2157-7579.1000146

as the areas with highest density of domestic pig population in Thailand [4]. However, the information on wild boar population density is currently not available. Some important characteristics of each studied captive stetting are shown in Table 1.

The prevalence of the studied diseases was unknown in these locations and populations. Thus, sample size in this study was calculated based on $50 \%$ estimated prevalence with precision of $5 \%$ which resulted in highest number of samples required. A statistical package named SAMPSIZE was used in our sample size calculation (http://sampsize.sourceforge.net/iface/). Since the total number of animals in all these studied premises is low, all wild boars in each captive setting were required to be tested according to the calculation.

Between February and March 2009, fifty-two wild boars were captured for blood sample collection; 19, 16 and 17 samples were derived from commercial wild boar farm, wildlife breeding research station and the zoo respectively (sampling fraction $=95 \%, 100 \%$ and $100 \%)$. After collection and processing, serum samples were then securely delivered to serological laboratory of the Monitoring and Surveillance Center for Zoonotic Diseases in Wildlife and Exotic Animals, Faculty of Veterinary Science, Mahidol University within 24 hours.

\section{Laboratory examination}

All serum samples were serologically examined for antibodies to PRRSV and M. hyopneumoniae by ELISA methods according to manufacturer's instructions (IDEXX Laboratories, Inc., Westbrook, Maine, USA). S/P (sample to positive) ratio was used to determine seropositivity where $S$ is the difference between optical density of the sample and optical density of the negative control and $\mathrm{P}$ is the difference between optical density of the positive control and optical density of the negative control. Tested Samples were interpreted as seropositive for both PRRSV and M. hyopneumoniae when S/P ratio was equal or higher than 0.4 .

\section{Prevalence calculation}

True prevalence was calculated based on sensitivity and specificity of the tests. The sensitivity and specificity of the ELISA essay for PRRSV are $99.9 \%$ and $98.8 \%$ and the values are $37.3 \%$ and 98.6\% respectively for $M$. hyopneumoniae testing.

\section{Results}

The results of this study revealed that 13 out of 52 tested sera had antibodies against PRRSV (24\% true prevalence; 95\% CI: 0.14 $0.38)$. The true prevalence as high as $69 \%$ (95\% CI: $0.43-0.87)$ was found in wildlife breeding research station in Ratchaburi province. In contrast, relatively low value of true prevalence was observed in commercial wild boar farm in Phetchabun province and zoo in Chonburi province at $4 \%$ (95\% CI: $0.00-0.24)$ and 5\% (95\% CI: 0.00-0.27), respectively. M. hyopneumoniae was detected in 4 out of 52 tested samples (18\% true prevalence; 95\% CI: $0.04-0.46$ ) and M. hyopneumoniae positive sera were only found in wildlife breeding research station. The true prevalence at this captive setting was 66\% (95\% CI: 0.21-1.00). Seroprevalence of PRRSV and M. hyopneumoniae in all sampling locations was summarized in Table 2 and geographic locations of sample collecting sites together with true prevalence were shown in Figure 1.

\section{Discussion}

The highest true prevalence of PRRSV was detected in the wildlife breeding research station in Ratchaburi province, the province

\begin{tabular}{|c|c|c|c|}
\hline \multirow[b]{2}{*}{ Parameter } & \multicolumn{3}{|c|}{ Type of captive setting } \\
\hline & $\begin{array}{l}\text { Commercial wild boar } \\
\text { farm (VS) }\end{array}$ & $\begin{array}{l}\text { Wildlife breeding } \\
\text { research station (KS) }\end{array}$ & Zoo (KK) \\
\hline Number of wild boars & 20 & 16 & 17 \\
\hline Wild boar replacementstrategy & $\begin{array}{l}\text { Reproducing within the farm } \\
\text { and purchasing from other } \\
\text { farms }\end{array}$ & $\begin{array}{l}\text { Reproducing within the } \\
\text { station and obtaining } \\
\text { from donations }\end{array}$ & $\begin{array}{l}\text { Reproducing within the } \\
\text { zoo and obtaining from } \\
\text { donations }\end{array}$ \\
\hline Vaccination against PRRSV and M. hyopneumoniae & No & No & No \\
\hline \multicolumn{4}{|l|}{ Domestic pig density in the area of study site } \\
\hline 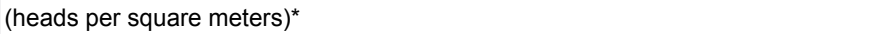 & $4.50-7.43$ & $147.00-777.56$ & 63.51-148.99 \\
\hline Prevalence of PRRSV in domestic pigs in the area of study site (\%) ${ }^{* *}$ & 53.6 & 35.1 & 30.5 \\
\hline Prevalence of M. hyopneumoniae in domestic pigs in the area of study site $(\%){ }^{* * *}$ & $N / A^{* * * *}$ & $2.08-45.00$ & $2.08-45.00$ \\
\hline
\end{tabular}

*Knips [4] ${ }^{* *}$ Tummaruk et al. [3], ${ }^{* *}$ Boonsoongnern et al. [6], ${ }^{* * *} \mathrm{~N} / \mathrm{A}=$ not available

Table 1: Some important characteristics of each studied captive setting and the area of study site.

\begin{tabular}{|c|c|c|c|c|c|c|c|c|c|}
\hline \multirow[t]{2}{*}{ Type of captive setting } & \multirow[t]{2}{*}{ Number tested } & \multicolumn{4}{|c|}{ PRRSV } & \multicolumn{4}{|c|}{ M. hyopneumoniae } \\
\hline & & $\begin{array}{l}\text { Number } \\
\text { positive }\end{array}$ & $\begin{array}{c}\text { Appearance } \\
\text { prevalence }\end{array}$ & $\begin{array}{c}\text { True } \\
\text { prevalence }\end{array}$ & $95 \% \mathrm{Cl}^{*}$ & $\begin{array}{l}\text { Number } \\
\text { positive }\end{array}$ & $\begin{array}{c}\text { Appearance } \\
\text { prevalence }\end{array}$ & $\begin{array}{c}\text { True } \\
\text { prevalence }\end{array}$ & $95 \% \mathrm{Cl}^{*}$ \\
\hline Commercial wild boar farm (VS) & 19 & 1 & 0.05 & 0.04 & $0.00-0.24$ & 0 & 0 & 0 & $0.00-0.43$ \\
\hline Wildlife breeding research station (KS) & 16 & 11 & 0.69 & 0.69 & $0.43-0.87$ & 4 & 0.25 & 0.66 & $0.21-1.00$ \\
\hline Zoo (KK) & 17 & 1 & 0.06 & 0.05 & $0.00-0.27$ & 0 & 0 & 0 & $0.00-0.49$ \\
\hline Overall & 52 & 13 & 0.25 & 0.24 & $0.14-0.38$ & 4 & 0.07 & 0.18 & $0.04-0.46$ \\
\hline
\end{tabular}

* $95 \% \mathrm{Cl}=95 \%$ Confidence Interval

Table 2: Number of samples tested and number of positive samples as well as prevalence for porcine reproductive and respiratory syndrome virus (PRRSV) and Mycoplasma hyopneumoniae in wild boars derived from three different types of captive settings including a commercial wild boar farm (VS), a wildlife breeding research station (KS) and a zoo (KK) in Thailand. The sensitivity and specificity of the ELISA essay for PRRSV are $99.9 \%$ and $98.8 \%$ and the values are $37.3 \%$ and $98.6 \%$ respectively for Mycoplasma hyopneumoniae testing. 
Citation: Wiratsudakul A, Prompiram P, Pholtep K, Tantawet S, Suraruangchai D, et al. (2013) TA Cross-Sectional Study of Porcine Reproductive and Respiratory Syndrome Virus and Mycoplasma hyopneumoniae in Wild Boars Reared in Different Types of Captive Setting in Thailand. J Veterinar Sci Technol 4: 146. doi:10.4172/2157-7579.1000146

Page 3 of 4

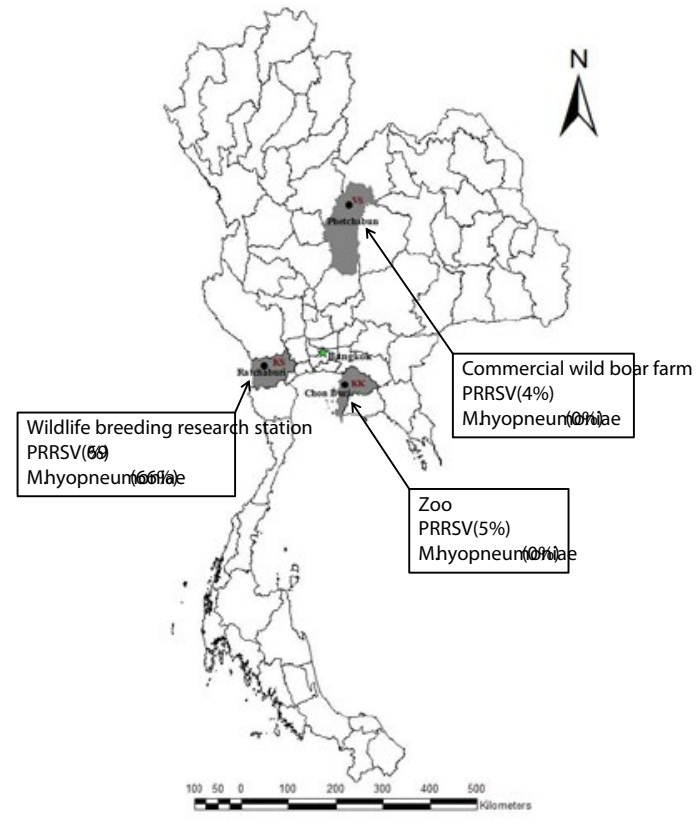

Figure 1: Geographic locations of the three sampling sites. True prevalence of porcine reproductive and respiratory syndrome virus (PRRSV) and Mycoplasma hyopneumoniae is indicated in the parentheses in the boxes with arrows pointing to each premise.

where co-circulation of multiple clusters from two genotypes of PRRSV in domestic pigs was reported [9]. Besides, Ratchaburi is the province that possessed highest record of domestic pig density in Thailand [4]. With this high density and co-circulation of multiple clusters of PRRSV in the province, it is possible that this particular pathogen was shared between wild boars and domestic pigs reared in this area. An in-depth investigation is needed to explore the genetic linkage of the PRRSV found in domestic pigs and wild boars and further determine whether wild boars can serve as reservoir of the disease for domestic pigs in that location. Nevertheless, only $2 \%$ seropositivity of PRRSV was found in wild boars population lived in the wild in a previous study conducted in the US [1]. It is noticeable that prevalence of PRRSV found in captive wild boars in the current study was much higher than the prevalence detected in free-ranging wild boars in the previous work. It is possible that more contacts between animals in captive settings trend to increase disease prevalence compared to the same species that lives in the wild. However, low level of prevalence of antibodies to PRRSV was found in the commercial wild boar farm and the zoo. More study sites and samples are required to conclude the overall PRRSV infectious status of captive wild boars in Thailand.

M. hyopneumoniae positive samples were found only in wildlife breeding research station where the highest prevalence of PRRSV was observed. It is coincided with the previous work which pointed out that M. hyopneumoniae and PRRSV are frequently found in combination [10]. Moreover, the prevalence of M. hyopneumoniae in this captive setting was in agreement with the previous publication conducted in wild boars in Slovenia [11].

The specificity of both ELISA assays used in this study is high (98.8\% for PRRSV and $98.6 \%$ for M. hyopneumoniae). False positive is not likely to occur. Hence, only one positive sample against PRRSV found in both commercial wild boar farm and the zoo is likely to be true positive. In contrast, the sensitivity of ELISA assay used for PRRSV is high (99.9\%) while it is relatively low (37.3\%) in the test for M. hyopneumoniae. False negative results trend to occur from the latter assay. Low and undetected M. hyopneumoniae seropositive samples might result from low sensitivity of the test. Number of $M$. hyopneumoniae positive wild boars in these populations may higher than the results shown in this study. A combination of multiple serological assays for testing $M$. hyopneumoniae is recommended in the further study in order to increase testing sensitivity and assist in an accurate diagnosis of M. hyopneumoniae in the population [12].

Furthermore, a sample derived from this wildlife breeding research station was the only one hepatitis virus positive sample found in a previous study conducted in the same populations as in the present study [8]. The possible reason for detecting multiple pathogens in this captive setting is likely associated with the source of animals. The animals reared in this wildlife station were mostly adopted from different unknown sources at different times while the sources of wild boars in the commercial wild boar farm and the zoo were well identified. It was suggested from previous study that introducing of infected replacement pigs into the farm was an important factor of PRRSV spreading in Thailand [5] and PRRSV can persist in pig's uterine tissue for several months [13]. The persistent infection also occurs in case of M. hyopneumoniae. The infected pigs can be convalescent carriers of M. hyopneumoniae for up to 200 days [14]. The previous studies also revealed that antibodies against PRRSV and M. hyopneumoniae can persist in the infected pigs for more than 28 [15] and 12 [16] months post infection respectively. Thus, the seropositive results found in this study can reflect the infections happened in these populations in many months earlier. However, antibody detection methods were used instead of detecting the antigens. The current infectious status of the animals in these settings was not known.

The persistency of these two pathogens is likely to allow the diseases to silently infect the animals unnoticeably after the replacement wild boars were introduced into the captive settings. Therefore, it is suggested that the newly introduced animals should be tested for important infected pathogens such as PRRSV and $M$. hyopneumoniae and should be quarantined before introducing into the herds.

\section{Conclusion}

The present study illustrated the picture of PRRSV and $M$. hyopneumoniae seropositivity in three premises representing three types of wild boar captive settings. More locations and samples are required in order to obtain more accurate infectious status of these diseases in Thailand. Since PRRSV and M. hyopneumoniae are prevalent elsewhere such as USA in feral wild boars that habit in the wilds [1], the future study should also expand to this type of population.

This study is the first to report seroprevalence of antibodies to PRRSV and M. hyopneumoniae in wild boar populations in Thailand. More detailed investigations are critically needed.

\section{Acknowledgements}

This study obtained financial supports from The Monitoring and Surveillance Center for Zoonotic Diseases in Wildlife and Exotic Animals, Faculty of Veterinary Science, Mahidol University. The authors gratefully thank all staffs in all captive settings for supporting us in animal restraint and facilitating this study. The authors are grateful to the two reviewers for their valuable comments and suggestions. 
Citation: Wiratsudakul A, Prompiram P, Pholtep K, Tantawet S, Suraruangchai D, et al. (2013) TA Cross-Sectional Study of Porcine Reproductive and Respiratory Syndrome Virus and Mycoplasma hyopneumoniae in Wild Boars Reared in Different Types of Captive Setting in Thailand. J Veterinar Sci Technol 4: 146. doi:10.4172/2157-7579.1000146

\section{References}

1. Baker SR, O'Neil KM, Gramer MR, Dee SA (2011) Estimates of the seroprevalence of production-limiting diseases in wild pigs. Vet Rec 168: 564.

2. Sibila M, Mentaberre G, Boadella M, Huerta E, Casas-Diaz E, et al. (2010) Serological, pathological and polymerase chain reaction studies on Mycoplasma hyopneumoniae infection in the wild boar. Vet Microbiol 144 214-218.

3. Tummaruk $P$, Surapat $P$, Sriariyakun $S$, Seemakram $O$, Olanratmanee EO, et al. (2012) Porcine reproductive and respiratory syndrome virus detection in Thailand during $2005-2010$ in relation to clinical problems, pig types, regions, and seasons. Trop Anim Health Prod 45: 771-779.

4. Knips $V(2004)$ Review of the livestock sector in the Mekong countries. Livestock Information, Sector Analysis and Policy Branch (AGAL), Food and Agriculture Organization of the United Nations.

5. Thanawongnuwech R, Amonsin A, Tatsanakit A, Damrongwatanapokin S (2004) Genetics and geographical variation of porcine reproductive and respiratory syndrome virus (PRRSV) in Thailand. Vet Microbiol 101: 9-21.

6. Boonsoongnern $A$, Jirawattanapong $P$, Lertwatcharasarakul $P$, Phatthanakunanan S, Poolperm P, et al. (2012) The Prevalence of Mycoplasma hyopneumoniae in Commercial Suckling Pigs in Thailand World J Vaccine 2: 161-163.

7. Otake S, Dee S, Corzo C, Oliveira S, Deen J (2010) Long-distance airborne transport of infectious PRRSV and Mycoplasma hyopneumoniae from a swine population infected with multiple viral variants. Vet Microbiol 145 198-208.

8. Wiratsudakul A, Sariya L, Prompiram $P$, Tantawet S, Suraruangchai D, et al. (2012) Detection and phylogenetic characterization of hepatitis $E$ virus genotype 3 in a captive wild boar in Thailand. J Zoo Wildl Med 43: 640-644

9. Tun HM, Shi M, Wong CL, Ayudhya SN, Amonsin A, et al. (2011) Genetic diversity and multiple introductions of porcine reproductive and respiratory syndrome viruses in Thailand. Virol J 8: 164

10. Thacker EL, Halbur PG, Ross RF, Thanawongnuwech R, Thacker BJ (1999) Mycoplasma hyopneumoniae potentiation of porcine reproductive and respiratory syndrome virus-induced pneumonia. J Clin Microbiol 37: 620-627.

11. Vengust G, Valencak Z, Bidovec A (2006) A serological survey of selected pathogens in wild boar in Slovenia. J Vet Med B Infect Dis Vet Public Health 53: $24-27$

12. Erlandson KR, Evans RB, Thacker BJ, Wegner MW, Thacker EL (2005) Evaluation of three serum antibody enzyme-linked immunosorbent assays for Mycoplasma hyopneumoniae. J Swine Health Prod 13: 198-203.

13. Olanratmanee EO, Wangnaitham $S$, Thanawongnuwech $R$, Kunavongkrit A, Tummaruk $P$ (2011) Prevalence of porcine reproductive and respiratory syndrome virus (PRRSV) antigen-positive uterine tissues in gilts culled due to reproductive disturbance in Thailand. Trop Anim Health Prod 43: 451-457.

14. Pieters M, Pijoan C, Fano E, Dee S (2009) An assessment of the duration of Mycoplasma hyopneumoniae infection in an experimentally infected population of pigs. Vet Microbiol 134: 261-266

15. Desrosiers R, Boutin M (2002) An attempt to eradicate porcine reproductive and respiratory syndrome virus (PRRSV) after an outbreak in a breeding herd: eradication strategy and persistence of antibody titers in sows. J Swine Health Prod 10: 23-25.

16. Grosse Beilage E, Rohde N, Krieter J (2009) Seroprevalence and risk factors associated with seropositivity in sows from 67 herds in north-west Germany infected with Mycoplasma hyopneumoniae. Prev Vet Med 88: 255-263. 